\title{
On the Use of the Gompertz Model to Predict Microbial Thermal Inactivation Under Isothermal and Non-Isothermal Conditions
}

\author{
Maria M. Gil • Fátima A. Miller • \\ Teresa R. S. Brandão · Cristina L. M. Silva
}

Keywords Gompertz model - Inactivation kinetics ·

Isothermal and non-isothermal conditions

\begin{abstract}
Food processes should be designed to provide an adequate margin of safety against microbiological risk of food poisoning and food spoilage throughout shelf life. In this field, the use of mathematical models that describe the microorganisms' kinetics in such conditions is an important tool for convenient design, control and optimization of efficient processes. If those models are accurate and precise, one can extract the best aiming at predictive purposes. The Gompertz equation is commonly applied to describe sigmoidal kinetics. Besides the proven adequacy of the model in those kinetics descriptions, most of the reported works do not use Gompertz equation in the most convenient form, and insightful information could be obtained with re-parameterized forms. This work aims at reviewing the use of the Gompertz model to describe inactivation, as well as re-parameterized forms that include parameters related to the survival curve features. Microbial survival often presents a shoulder prior to inactivation, followed by a linear phase (corresponding to a maximum inactivation rate) and a tail residual population. The versatility of the Gompertz model in describing kinetics with different shapes, varying from a log-linear tendency till a complete sigmoidal shape, makes it attractive for predictive purposes, both under static and dynamic temperature
\end{abstract}

M. M. Gil

ESTM, GIRM, Instituto Politécnico de Leiria, 2520-064

Peniche, Portugal

M. M. Gil · F. A. Miller · T. R. S. Brandão - C. L. M. Silva ( $\square)$ $\mathrm{CBQF}$, Escola Superior de Biotecnologia, Universidade Católica Portuguesa, Rua Dr. António Bernardino de Almeida, 4200-072 Porto, Portugal

e-mail: clsilva@esb.ucp.pt conditions. Drawbacks and critical features of the model, when it is applied to microbial responses, will be overview.

\section{List of Symbols}

a Gompertz model parameter (Eq. 1)

A Maximum microbial cell density (Eq. 2) or Gibson modified Gompertz model parameter (Eq. 3)

$b \quad$ Gompertz model parameter (Eq. 1)

$B \quad$ Gibson modified Gompertz model parameter (Eq. 4)

c Gompertz model parameter (Eq. 1)

C Gibson modified Gompertz model parameter (Eq. 3)

D Model parameter

e Euler's number (2.71828)

$k \quad$ Inactivation rate $\left(\mathrm{min}^{-1}\right)$

$L \quad$ Lag time or shoulder (min)

$M \quad$ Gibson modified Gompertz model parameter (Eq. 3)

$N \quad$ Microbial cell density $\left(\mathrm{CFU} \mathrm{m}{ }^{-1}\right)$

$R_{\text {adj }}^{2} \quad$ Coefficient of determination adjusted

$t \quad$ Time (s or min)

$y$ Dependent variable

Greek

$\mu \quad$ Specific microbial growth rate $\left(\mathrm{s}^{-1}\right.$ or $\left.\mathrm{min}^{-1}\right)$

\section{Subscripts}

dynamic Relative to non-isothermal conditions

$i \quad$ At the function inflexion point

inact Relative to inactivation

$\max \quad$ Maximum value

orig Relative to original Gompertz model

$0 \quad$ Initial value

res Residual value 


\section{Abbreviations}

SHW $_{95 \%}$ Standardized half width at $95 \%(\%)$

\section{Introduction}

Food microbiologists are giving increased attention to microbial kinetics modelling. The use of mathematical models that properly describe microbial behaviour under specific environmental conditions is important for predictive purposes and process design.

Whereas growth kinetic models are helpful for estimation of the time required for pathogens to reach dangerous levels under specific conditions, inactivation kinetic models allow prediction of pathogens survival under stressing environmental factors (such as high temperatures, low $\mathrm{pH}$ and reduced water activity values). Inactivation models may contribute to determine the extent to which existing thermal food processes could be modified in order to improve shelf life and quality, while maintaining safe standards.

First-order kinetic models have been extensively used to describe a log-linear microbial variation with time. However, growth/survival curves of most microbial cells do not show such tendency [42], and a sigmoidal behaviour is often observed. These curves can be characterized by three main features: (1) a lag time (or shoulder) prior to a (2) maximum growth/inactivation rate period and a (3) tail (or residual population).

Valuable reviews on microbial kinetics modelling were done by Ross and McMeekin [35], Schaffner and Labuza [36], McDonald and Sun [26], Xiong et al. [47], Xiong et al. [48] and Geeraerd et al. [14]. Concerning the dependence of the kinetic parameters with adverse factors, the works of Whiting and Buchanan [45] and Swinnen et al. [39] are supportive references. Zwietering et al. [49] and Buchanan et al. [7] compared the most relevant models used to describe microbial growth. Regarding thermal inactivation behaviour, Xiong et al. [48] gathered the most frequently used mathematical expressions. Those models describe linear and nonlinear curves, with shoulder and/or tailing phases [10,21, $22,32,34]$. The Gompertz and logistic functions and the Baranyi model are the most widely used expressions to describe sigmoidal microbial kinetics [2, 29].

There is a never-ending discussion about the best models (mechanistics, empiricals and stochastics) applied in this field. However, one should bear in mind that an adequate model can be considered the one that predicts the response accurately, if this is the objective, and several models may attain such target.

Mathematical models for microbial inactivation prediction are usually developed on the basis of un-realistic isothermal conditions [34], and thermal inactivation studies related to real food processes, considering actual timevarying temperature conditions, are scarce $[6,12,24,37]$. Parameters estimated under isothermal conditions differ from the ones obtained if non-isothermal conditions are applied [20, 41], and hazardous predictions maybe attained if parameters estimated isothermally were used to predict bacterial survival under time-varying temperature conditions.

\section{The Gompertz Model}

Gibson et al. [15], Zwietering et al. [49], Garthright [13] and Chhabra et al. [9] referred the versatility of the Gompertz model in describing log-linear kinetics as well as those containing shoulder and/or tailing effects.

The Gompertz equation [18], which is a three-parameter model, was firstly developed to express the law of human mortality. Gibson et al. [15] were pioneers in using this mathematical expression to describe asymmetrical sigmoid shape of microbial growth:

$y_{\text {orig }}(t)=a \exp (-\exp (b-c t))$

Herein, $y_{\text {orig }}$ represents the observed response at time $t$, and $a, b$ and $c$ are model parameters (assumed to be positive). In Fig. 1, it can be observed the influence of these parameters on the function shape. With exception of the parameter $a$ that expresses the upper limit of the function, the remaining two parameters do not give direct information on a unique curve feature.

Equation 1, and its modified forms, has been successfully applied to describe isothermal microbial growth [1, $16,23,28,38]$ and isothermal microbial inactivation [5, $8,19,24,25,47]$. McDonald and Sun [26] concluded that the Gompertz expression was the best model to describe growth tendencies, both in terms of statistical accuracy and form simplicity, when compared to other sigmoidal functions. Gibson et al. [15] arrived to similar conclusions.

Besides the extensive use of the Gompertz model, it is not clear the methodology to attain a re-parameterization of the function aiming at obtaining parameters that express a feature of the growth/survival curves. Only a small number of works linked model parameters to a microbiological occurrence, i.e. growth/survival rate and lag time/shoulder $[13,49]$, thus confining the advantages of using mathematical expressions in phenomena description.

Zwietering et al. [49] re-parameterized the original Gompertz equation to describe isothermal microbial growth, considering the maximum specific growth rate $\left(\mu_{\max }\right)$, the lag time $(L)$ and the maximum reached value $(A)$ as model kinetic parameters: 
Fig. 1 Influence of the original Gompertz parameters on the function shape: a parameter a, b parameter $\mathrm{b}$ and $\mathbf{c}$ parameter $\mathrm{c}$ (a)

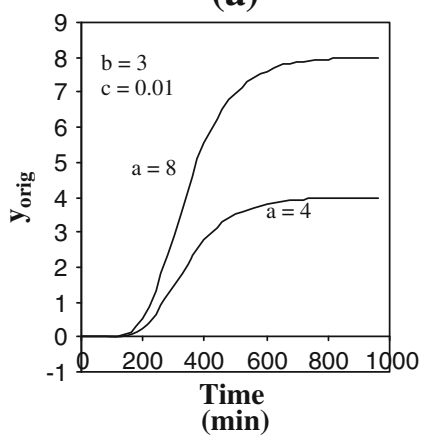

(b)

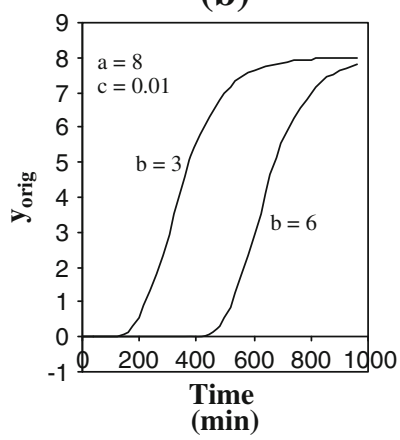

(c)

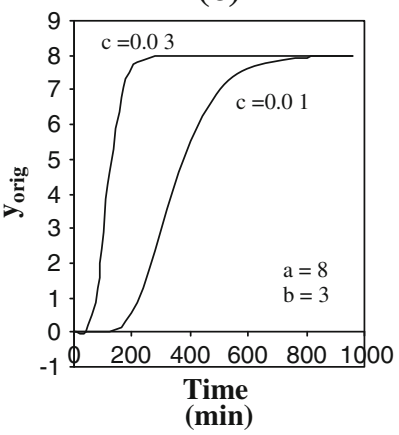

$\ln \left(\frac{N}{N_{0}}\right)=A \exp \left\{-\exp \left[\frac{\mu_{\max } \exp (1)}{A}(L-t)+1\right]\right\}$

where $N$ is the population density at time $t$ (the index 0 denotes initial values).

Gibson et al. [15] also proposed a modification for the Gompertz equation, as follows:

$\log N=A+C \exp \{-\exp [-B(t-M)]\}$

and considered:

Growth rate $=\frac{B C}{e}$

$\operatorname{lag}=M-\frac{1}{B}$

Generation time $=\frac{24 \times \log (2) \times \exp (1)}{B \times C}$

where the generation time is the time at which the absolute growth rate is maximum.

Expressions 2 and 3 are identical, if Eq. 3 is normalized in relation to $N_{0}$. Zwietering et al. [49] expressed $\ln \left(N / N_{0}\right)$ as a function of time, while Gibson et al. [15] used $\log (N)$.

Some authors found that the growth rate of the modified Gompertz equation is most of the times significantly larger than the growth rate identified by an exponential model or by the Baranyi model [2]. In Baty and Delignette-Muller [4], it is stated that: "The limitations in the use of the modified Gompertz model have been widely discussed, attention being particularly paid to the overestimation of $\mu_{\max }$ and lag time". However, these affirmations are based on the works of Whiting and Cygnarowicz-Provost [46], Dalgaard [11], Membre et al. [30] and McKellar and Knight [27] and, besides the remarkable approach of Baty and Delignette-Muller [4] about estimation of lag time, these authors were not critical about the works they had based their conclusions. In such works, model parameters were estimated, but uncertainty was not quantified (e.g. confidence intervals). The unknown parameter should not be evaluated by the estimated value itself, but should be assessed by the interval within the true value of the parameter is expected to lie, based on a pre-establish significance level (i.e. confidence intervals that allows comparison of precision of different parameters). Consequently, saying that an overestimation occurs (Dalgaard [11] referred that an overestimation of $10-20 \%$ was observed for $\mu_{\max }$ ) is limited to the value of the estimates. Obviously, this is a confined conclusion, and there is no statistical evidence that an overestimation had been attained.

\section{Modifications of the Gompertz Model to Describe Inactivation}

Different approaches had been proposed to modify the original Gompertz model to describe inactivation. Nevertheless, a critical review of the drawbacks/advantages of those modified and re-parameterized functions is lacking.

If experimental data is normalized in order to $N_{0}$, it is possible to compare kinetic behaviour of experimental data with different initial inoculum's size. In the work of Miller et al. [31], the assumed dependent variable was the logarithm of the normalized values of the microbial $\operatorname{load}, \log \left(N / N_{0}\right)$. The symmetric about the $x$-axis of the original Gompertz equation for growth (i.e. replacing $y$ by $-y$ in its original form) was assumed for inactivation (Table 1, Approach 1).

Linton et al. [24] also considered $\log \left(N / N_{0}\right)$ as the dependent variable, and the mathematical function for inactivation was obtained by subtracting the original Gompertz expression at time zero from the one at time $t$ (Table 1, Approach 2).

Gil et al. [17] assumed that the dependent variable was the logarithm of the microbial load, $\log N$, and the original Gompertz equation was subtracted from a constant (Table 1, Approach 3).

According to Garthright [13], the reason for applying logarithmic of different bases (i.e. $\ln$ or $\log$ ) to microbial content is not stated. The only difference is related to the vertical axis scale. However, and as microbiological dilutions are powers of 10 , "log" is a more convenient form. 


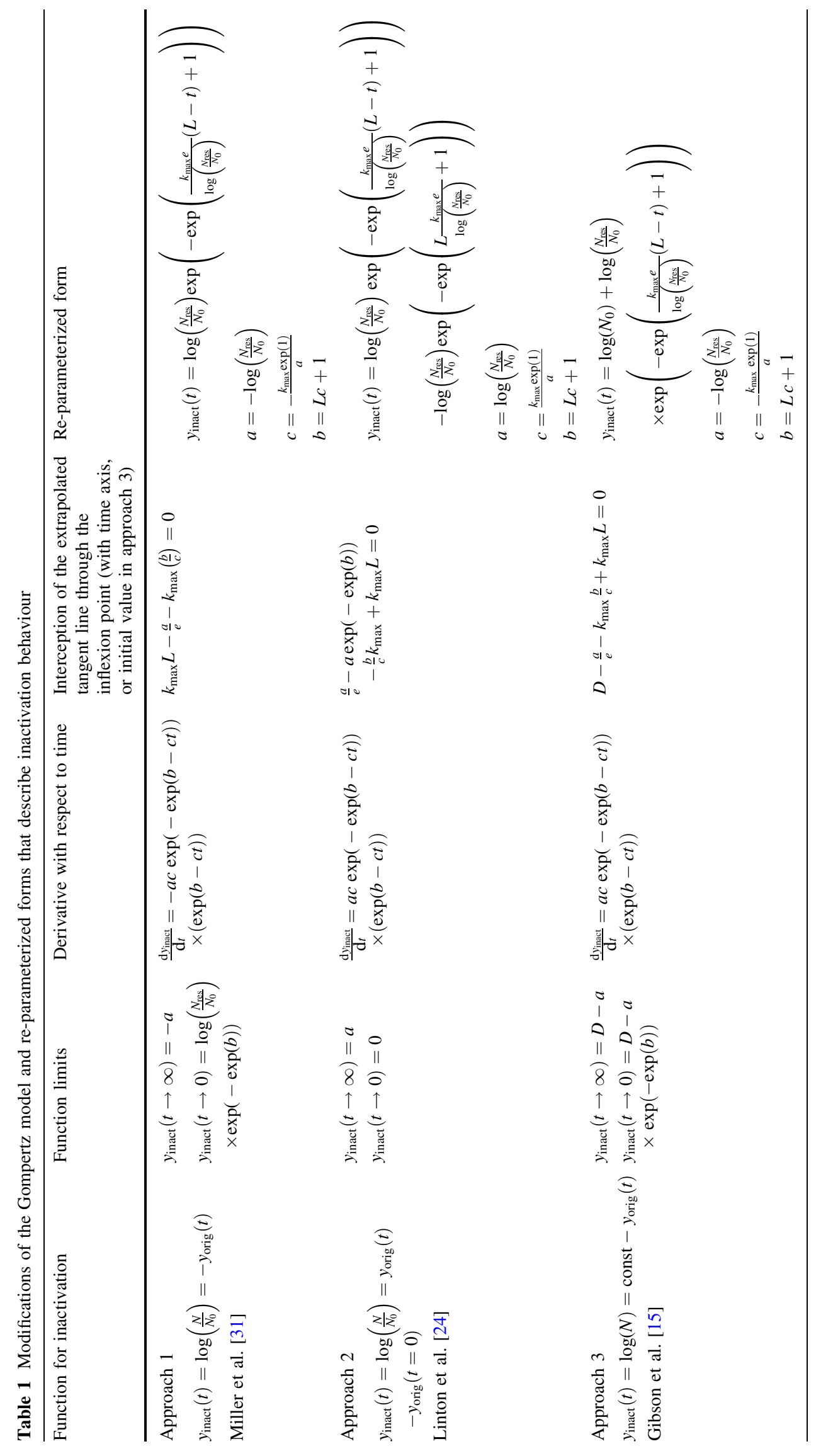


Analytical Study of the Functions

Based on functions' analytical study (e.g. function limits and derivatives), inactivation functions can be re-parameterized in more convenient expressions.

The tail effect, which is a residual population, can be estimated by the asymptote of the function. Maximum inactivation rate can be obtained by calculating the first derivative at the curve inflexion point, $t_{i}$. The shoulder can be determined by the interception of the extrapolated tangent line with time axis (Table 1, approaches 1 and 2) or with initial value (Table 1 , approach 3 ).

To clarify this methodology in the re-parameterization of the Gompertz model for inactivation, an example will be shown considering the approach 1 . The dependent variable assumed is:

$y_{\text {inact }}(t)=\log \left(\frac{N}{N_{0}}\right)=-y_{\text {orig }}(t)$

\section{Function Limits}

The residual population $\left(N_{\text {res }}\right.$, i.e. microbial load when time is considerably high) and initial microbial content $\left(N_{0}\right.$, i.e. microbial load when time is zero) can be calculated by function limits.

If $t \rightarrow \infty \Rightarrow y_{\text {inact }} \rightarrow-a$ Thus, parameter $a$ can be substituted by $\log \left(\frac{N_{0}}{N_{\text {res }}}\right)$ or $(-a)$ substituted by $\log \left(\frac{N_{\text {res }}}{N_{0}}\right)$, corresponding to the tailing effect (asymptotic value).

Regarding the initial value:

$t \rightarrow 0 ; \quad y_{\text {inact }} \rightarrow \log \left(\frac{N_{\text {res }}}{N_{0}}\right) \exp (-\exp (\mathrm{b}))$

At $t=0, \log N(t=0)=\log N_{0}$, so $y_{\text {inact }}(0)=0$. However, this is only observed if parameter $b$ is high.

If $b$ has a low value, then $y_{\text {inact }}(0)$ is not zero, being $y_{\text {inact }}(0)=\frac{\log \left(\frac{N_{\text {res }}}{N_{0}}\right)}{e}$. Nevertheless, this value is very small compared to $\log \left(N_{\text {res }} / N_{0}\right)$. The significance of this problem will be discussed later.

\section{Function Derivatives}

The maximum inactivation rate, $k_{\max }$, can be obtained by calculating the function first derivative at the inflection point, $t_{i}$ (determined by the zero of the second-order derivative):

$\frac{\mathrm{d} y_{\text {inact }}}{\mathrm{d} t}=-a c \exp (-\exp (b-c t))(\exp (b-c t))$

Substituting $t$ by $t_{i}=\frac{b}{c}$, one can obtain:

$k_{\max }=\left.\frac{\mathrm{d} y_{\text {inact }}}{\mathrm{d} t}\right|_{t=t_{i}}=-\frac{a c}{e}$ thus, parameter $c$ can be re-written as:

$c=-\frac{k_{\max } e}{a}=\frac{k_{\max } e}{\log \left(\frac{N_{\text {res }}}{N_{0}}\right)}$

The shoulder, $L$, is defined as the interception of the extrapolated tangent line through the inflexion point with time axis (or initial value in approach 3 ):

$k_{\max } L-\frac{a}{e}-k_{\max }\left(\frac{b}{c}\right)=0$

If Eqs. 11 and 12 are merged, parameter $b$ can be expressed as:

$b=1-\frac{L k_{\max } e}{a}$

A re-parameterized expression for $y_{\text {inact }}(t)$ can be obtained by substitution of parameters $a, b$ and $c$ into Eq. 7:

$y_{\text {inact }}(t)=\log \left(\frac{N_{\text {res }}}{N_{0}}\right) \exp \left(-\exp \left(\frac{k_{\max } e}{\log \left(\frac{N_{\text {res }}}{N_{0}}\right)}(L-t)+1\right)\right)$

with the following parameters: shoulder $(L)$, maximum inactivation rate $\left(k_{\max }\right)$ and tail $\left[\log \left(N_{\text {res }} / N_{0}\right)\right]$.

An outline of the analytical study of Gompertz-based functions, modified for inactivation, is in Table 1 .

\section{Drawbacks/Advantages of Re-parameterized Gompertz Functions}

Concerning approach 1 and as discussed before, the function at time zero $\left[\log \left(N / N_{0}\right)(t=0)\right]$ only approaches zero.

However, if the $b$ parameter is higher than 1.6 (i.e. the ratio between $\left(k_{\max } L\right)$ and $\log \left(N_{\text {res }} / N_{0}\right)$ is higher than 0.22), which is verified for microbial inactivation as mentioned by Van Impe et al. [43] and Garthright [13], then the overestimation in $\log \left(N / N_{0}\right)$ will be approximately $5 \%$. This value is lower than the variations occurring between duplicates of microbial enumerations, which commonly vary between 10 and $60 \%$.

The drawback in estimation microbial loads at time zero also appears in approach 2. Re-parameterization is only possible if the parameter $b$ is high; otherwise, there is some inconsistency from a mathematical point of view.

Additionally, and in both approaches 1 and 2, $y_{\text {inact }}(t \rightarrow$ $\infty)$ only approximates to $\log \left(N_{\text {res }} / N_{0}\right)$. This can be overcome by $b$ value restrictions, as previously discussed. Nevertheless, both problems are limitations from a mathematical point of view and not from a biological aspect. In order to circumvent those weaknesses, an additional parameter was included in approach 3 (parameter $D$ ). 
Gibson et al. [15] used this modified equation to avoid fitting problems at initial time. The mathematical study of the re-parameterized modification shows that $y_{\text {inact }}(0)$ is only equal to $\log \left(N_{0}\right)$ when $b \rightarrow \infty$, if not $D$ can be a very poor estimator of $\log \left(N_{0}\right)$.

\section{Non-isothermal Conditions}

Non-isothermal conditions are more complex situations, as the temperature histories affect parameter estimation. The kinetic parameters estimated under time-varying temperature conditions may differ from the ones predicted at constant temperatures. Using the later ones, in situations in which the temperature varies with the time, may affect the predictive ability of the model [17].

Nicolaï and Van Impe [33] and Geeraerd et al. [14] were innovative in the way they approached the modelling of microbial growth and/or inactivation under dynamic temperature conditions. The works of Van Impe et al. [43] and Huang [19] were the first to refer Gompertz model modifications for non-isothermal conditions, including the temperature variations throughout the process.

According to Gil et al. [17], the mathematical expression for non-isothermal conditions can be obtained by differentiating the isothermal re-parameterized model with respect to time:

$y_{\text {dynamic }}(\mathrm{t})=\int_{0}^{t} \frac{\mathrm{d} y_{\text {inact }}(t)}{\mathrm{d} t} \mathrm{~d} t$

The model parameters, shoulder and maximum inactivation rate, are temperature dependent. In processes in which temperature varies with time, those parameters are obviously time-temperature relying. If the dependence of kinetic parameters on temperature is expressed mathematically and if the temperature history is known, those relationships may be included in Eq. 15. A mathematical model that describes the microbial content throughout time and temperature can thus be obtained.

Three main assumptions should be in the backstage of the model development, as highlighted in Valdramidis et al. [40]: (1) no microbial growth occurs during the comeup time of the non-isothermal heat treatment; (2) there is a limit of temperature below which no inactivation is observed (i.e. inactivation rate is set to zero for temperatures lower than this limit) and (3) the temperature history has not a significant effect on the microbial heat resistance.

Huang [19] compared three mathematical models (linear, Weibull- and Gompertz-type models) to describe the inactivation of L. Monocytogenes in ground beef under both isothermal and non-isothermal conditions and concluded that the Gompertz was the only one capable of quantifying the behaviour in non-isothermal conditions.

\section{A Case Study}

A case study is presented to assess the three approaches outline. Listeria innocua thermal inactivation data in broth under isothermal conditions were considered at temperatures of 52.5, 55.0, 57.5, 60.0, 62.5 and $65.0{ }^{\circ} \mathrm{C}$ (data from [31]. The three functions that can be used for inactivation (Table 1) were fitted to experimental data by nonlinear regression analysis. All regression analysis procedures and calculations were performed in programs specially written in FORTRAN 77 language (Fortran 5.1, Microsoft Corporation $\left.^{\circledR}, 1990\right)$.

Results of data fits to experimental points are in Fig. 2; estimates of the parameters and results of regression analyses are shown in Table 2. Comparing the three re-parameterizations, one can conclude that all approaches are quite similar. Besides this similarity, it can be found that re-parameterized equations obtained in approaches 2 and 3 have problems, mainly when fitting experimental data without shoulder region or residual population (tail effect). In approach 3, this can be explained by the additional parameter $\log \left(N_{0}\right)$, which increases the collinearity.

It can be observed that all modified Gompertz models allowed accurate predictions of Listeria innocua inactivation in the temperature range considered $\left(R_{\text {adj }}^{2}\right.$ between 0.944 and 0.992 , which means that more than $94 \%$ of the total variation was explained by the model). The analysis

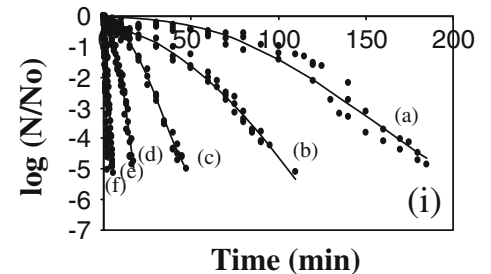

Time (min)
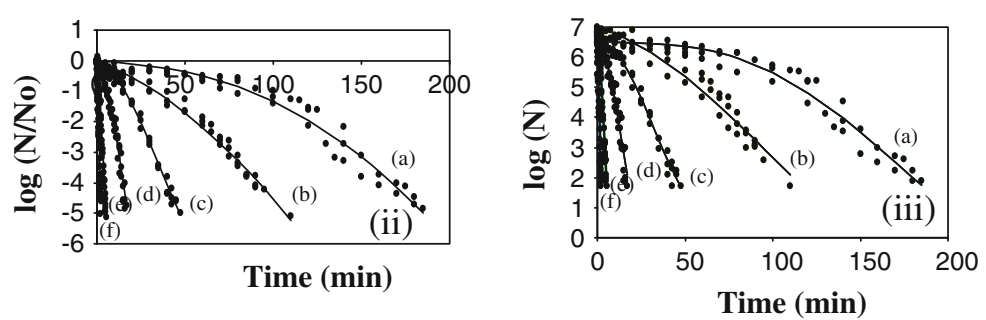

Fig. 2 Experimental data of thermal inactivation of Listeria innocua in broth (filled circle) and model fits (continuous line) at a $52.5^{\circ} \mathrm{C}$, $b 55.0{ }^{\circ} \mathrm{C}, c 57.5^{\circ} \mathrm{C}, d 60.0{ }^{\circ} \mathrm{C}, e 62.5^{\circ} \mathrm{C}, f 65.0^{\circ} \mathrm{C}$ : (i) approach 1 , (ii) approach 2 and (iii) approach 3 
Table 2 Parameters estimation and evaluation of precision; relevant statistical data of regression analysis

\begin{tabular}{|c|c|c|c|c|c|c|c|c|c|c|c|}
\hline \multirow[t]{2}{*}{ Function } & \multirow[t]{2}{*}{$T\left({ }^{\circ} \mathrm{C}\right)$} & \multirow[t]{2}{*}{$\log \left(N_{0}\right)$} & \multicolumn{3}{|c|}{ Parameter estimates } & \multicolumn{4}{|c|}{ Standard half width error } & \multicolumn{2}{|c|}{ Regression analysis } \\
\hline & & & $\log \left(N_{\text {res }} / N_{0}\right)$ & $\begin{array}{l}k_{\max } \\
\left(\min ^{-1}\right)\end{array}$ & $L(\min )$ & $\begin{array}{l}\mathrm{SHW}_{95 \%} \\
\log \left(N_{0}\right)\end{array}$ & $\begin{array}{l}\mathrm{SHW}_{95 \%} \\
\log \left(N_{\text {res }} / N_{0}\right)(\%)\end{array}$ & $\begin{array}{l}\mathrm{SHW}_{95 \%} \\
k_{\text {max }}(\%)\end{array}$ & $\begin{array}{l}\mathrm{SHW}_{95 \%} \\
L(\%)\end{array}$ & $R_{\mathrm{adj}}^{2}$ & $\begin{array}{l}\text { Residuals } \\
\text { normality }\end{array}$ \\
\hline \multirow[t]{6}{*}{ Approach 1} & 52.5 & - & -9.3 & -0.04 & 69.1 & - & 47.79 & 14.72 & 18.89 & 0.962 & Yes \\
\hline & 55.0 & - & -18.2 & -0.08 & 39.6 & - & 55.36 & 29.63 & 46.60 & 0.984 & Yes \\
\hline & 57.5 & - & -8.3 & -0.14 & 10.8 & - & 17.73 & 4.62 & 12.26 & 0.992 & Yes \\
\hline & 60.0 & - & -14.8 & -0.45 & 6.1 & - & 69.21 & 31.95 & 49.80 & 0.970 & Yes \\
\hline & 62.5 & - & -7.6 & -1.14 & 0.7 & - & 20.71 & 5.33 & 24.13 & 0.977 & Yes \\
\hline & 65.0 & - & -6.8 & -2.18 & 0.0 & - & 23.50 & 7.98 & 321.70 & 0.971 & Yes \\
\hline \multirow[t]{6}{*}{ Approach 2} & 52.5 & - & -36.2 & -0.08 & 129.0 & - & 227.00 & 136.20 & 108.90 & 0.966 & Yes \\
\hline & 55.0 & - & -35.0 & -0.08 & 40.0 & - & 351.30 & 168.50 & 394.60 & 0.975 & Yes \\
\hline & 57.5 & - & -9.5 & -0.14 & 9.3 & - & 32.26 & 5.80 & 18.51 & 0.991 & Yes \\
\hline & 60.0 & - & -14.3 & -0.40 & 4.0 & - & 122.70 & 38.00 & 80.90 & 0.969 & Yes \\
\hline & 62.5 & - & -10.1 & -1.10 & 0.0 & - & 59.66 & 6.65 & $\infty$ & 0.975 & Yes \\
\hline & 65.0 & - & -6.1 & -2.53 & 0.0 & - & 33.71 & 17.25 & $\infty$ & 0.956 & Yes \\
\hline \multirow[t]{6}{*}{ Approach 3} & 52.5 & 6.5 & -11.8 & -0.05 & 91.4 & 2.35 & 79.74 & 27.90 & 22.35 & 0.965 & Yes \\
\hline & 55.0 & 7.6 & -14.1 & -0.06 & 15.0 & 20.72 & 193.6 & 48.23 & 165.00 & 0.947 & Yes \\
\hline & 57.5 & 6.6 & -7.4 & -0.14 & 11.2 & 2.88 & 28.55 & 6.62 & 20.58 & 0.987 & Yes \\
\hline & 60.0 & 7.6 & -15.6 & -0.37 & 2.0 & 31.26 & 260.3 & 63.74 & 241.70 & 0.944 & Yes \\
\hline & 62.5 & 7.2 & -10.4 & -1.14 & 0.5 & 11.86 & 75.19 & 8.81 & 151.50 & 0.974 & Yes \\
\hline & 65.0 & 6.6 & -6.9 & -2.21 & 0.0 & 18.83 & 63.58 & 15.78 & $\infty$ & 0.967 & Yes \\
\hline
\end{tabular}

of the residuals showed that randomness was verified, as well as normality behaviour. A runs test [44] was carried out for detecting departures in randomness, and results proved that residuals were random in all cases. Overall, in terms of parameters' precision evaluated by the standardized half width of the estimates at $95 \%\left(\mathrm{SHW}_{95 \%}\right.$, i.e. halved confidence interval divided by the estimate $\equiv$ $\frac{\text { confidence interval }{ }_{95 \%}}{2} \times \frac{1}{\text { estimate }} \times 100$ ), better results were obtained when approach 1 was considered (i.e. lower $\mathrm{SHW}_{95 \%}$ values were obtained). For shoulder, $k_{\max }$ and tail, $\mathrm{SHW}_{95 \%}$ varied between $12-322 \%, 5-32 \%$ and $18-69 \%$, respectively. When higher temperatures were considered, lowest precision was obtained for shoulder parameter. This can be an indication of lack of fit that may be explained by the decrease in the initial shoulder time. In such situation, better results might be obtained if another experimental design was chosen.

Based on these results and on inference bands of $95 \%$, which are the prediction intervals for a future observed response [3], approach 1 was the elected one (Fig. 3). Nevertheless, the values of the estimated response for time zero only approaches zero. This limitation can be neglected when compared to the large experimental measuring error observed between initial inoculum's size duplicates (the difference between duplicates was within the range of $5.5-58 \%$, depending on the temperature). This can also be accepted if inference bands are taken into consideration.

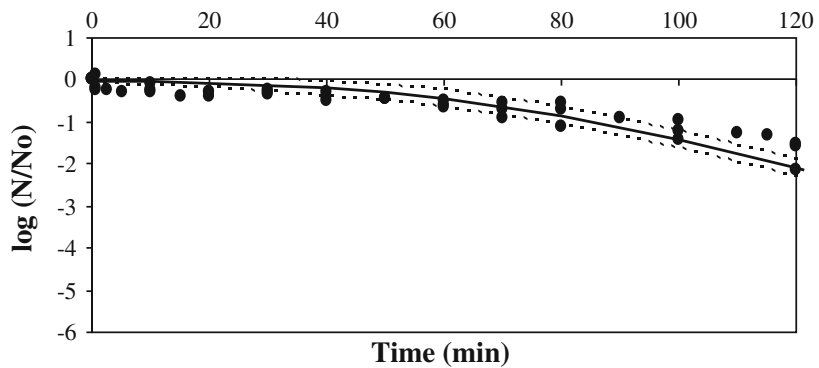

Fig. 3 Results from fitting the modified Gompertz model considering approach 1 (solid line) to the Listeria innocua inactivation data at $52.5{ }^{\circ} \mathrm{C}$ (filled circle). The dashed lines indicate the 95\% inference bands of the response

Note, however, that parameter estimates should be used with caution for temperatures outside the experimental isothermal region (i.e. $<52.5$ and $>65.0{ }^{\circ} \mathrm{C}$ ) where extrapolation is made.

\section{Concluding Remarks}

Among nonlinear models, the Gompertz equation and its modified forms have been successfully applied to describe inactivation, both in terms of statistical accuracy and easiness of use, when compared to other sigmoidal functions.

The Gompertz equation does not assume a constant death rate. Rather, it is a model that can be used to model 
death rates that change over time. However, there is a maximum value for the inactivation rate and $k_{\max }$ expresses this feature (maximum slope of the curve). In re-parameterized forms, $k_{\max }$ could be a model parameter, as well as the initial shoulder period and the tail residual population (when it occurs).

Besides the Gompertz model has some limitations from a mathematical point of view, it is effective for predictive purposes in microbial thermal inactivation responses, if convenient re-parameterized forms are applied.

Acknowledgments F. A. Miller and T. R. S. Brandão acknowledge financial support to Fundação para a Ciencia e Tecnologia (Portugal), via a Doctoral fellowship (SFRH/BD/11358/2002) and PostDoctoral fellowship (SFRH/BDP/11580/2002), respectively.

\section{References}

1. Andres SC, Giannuzzi L, Zaritzky NE (2001) Mathematical modelling of microbial growth in packaged refrigerated orange juice treated with chemical preservatives. J Food Sci 66:724-728

2. Baranyi J, Roberts TA (1994) A dynamic approach to predicting bacterial growth in food. Food Microbiol 23:277-294

3. Bates DM, Watts DG (1988) Nonlinear regression analysis and its applications. Wiley, New York

4. Baty F, Delignette-Muller ML (2004) Estimating the bacterial lag time: which model, which precision? Int J Food Microbiol 91: 261-277

5. Bhaduri S, Smith PW, Palumbo SA, Turner-Jones CO, Smith JL, Marmer BS, Buchanan RL, Zaika LL, Williams AC (1991) Thermal destruction of Listeria monocytogenes in liver sausage slurry. Food Microbiol 8:75-78

6. Buchanan RL, Golden MH, Whiting RC, Phillips JG, Smith JL (1994) Nonthermal inactivation models for Listeria monocytogenes. J Food Sci 59:179-188

7. Buchanan RL, Whiting RC, Damert WC (1997) When is simple good enough: a comparison of the Gompertz, Baranyi, and threephase linear models for fitting bacterial growth curves. Food Microbiol 14:313-326

8. Char C, Guerrero S, Alzadora SM (2009) Survival of Listeria iпnосиа in thermally processed orange juice as affected by vanillin addiction. Food Control 20:67-74

9. Chhabra AT, Carter WH, Linton RH, Cousin MA (1999) A predictive model to determine the effects of $\mathrm{pH}$, milkfat, and temperature on thermal inactivation of Listeria monocytogenes. J Food Prot 62:1143-1149

10. Cole MB, Davies KW, Munro G, Holyoak CD, Kilsby DC (1993) A vitalistic model to describe the thermal inactivation of Listeria monocytogenes. J Ind Microbiol 12:232-239

11. Dalgaard $P$ (1995) Modelling of microbial activity and prediction shelf life for packed fresh fish. Int J Food Microbiol 26:305-317

12. Dens EJ, Van Impe JF (2000) On the importance of taking space into account when modelling microbial competition in structured food products. Math Comput Simul 53:443-448

13. Garthright WE (1991) Refinements in the prediction of microbial growth curves. Food Microbiol 8:239-248

14. Geeraerd AH, Herremans CH, Van Impe JF (2000) Structural model requirements to describe microbial inactivation during a mild heat treatment. Int J Food Microbiol 59:185-209

15. Gibson AM, Bratchell N, Roberts TA (1987) The effect of sodium chloride and temperature on the rate and extent of growth of Clostridium botulinum type a in pasteurized pork slurry. J Appl Bacteriol 62:479-490

16. Gibson AM, Bratchell N, Roberts TA (1988) Predicting microbial growth-growth responses of Salmonellae in a laboratory medium as affected by $\mathrm{pH}$, sodium chloride and storage temperature. Int $\mathbf{J}$ Food Microbiol 6:155-178

17. Gil MM, Brandão TRS, Silva CLM (2006) A modified Gompertz model to predict microbial inactivation under time-varying temperature conditions. J Food Eng 76:89-94

18. Gompertz B (1825) On the nature of the function expressive of the law of human mortality, and on a new mode of determining the value of life contingencies. Philos Trans R Soc London 115:513-585

19. Huang L (2009) Thermal inactivation of Listeria monocytogenes in ground beef under isothermal and dynamic temperature conditions. J Food Eng 90:380-387

20. Janssen M, Verhulst A, Valdramidis V, Devlieghere F, Van Impe $\mathrm{JF}$, Geeraerd AH (2008) Inactivation model equations and their associated parameter values obtained under static acid stress conditions cannot be used directly for predicting inactivation under dynamic conditions. Int J Food Microbiol 128:136-145

21. Juneja VK, Eblen BS (1999) Predictive thermal inactivation model for Listeria monocytogenes with temperature, $\mathrm{pH}, \mathrm{NaCl}$ and sodium pyrophosphate as controlling factors. J Food Prot 62:986-993

22. Juneja VK, Marks HM (2003) Mathematical description of nonlinear survival curves of Listeria monocytogenes as determined in a beef gravy model system at 57.5 to $65{ }^{\circ} \mathrm{C}$. Innovat Food Sci Emerg Tech 4:307-317

23. Juneja VK, Melendres MV, Huang L, Gumudavelli V, Subbiah J, Thippareddi H (2007) Modeling the effect of temperature on growth of Salmonella in chicken. Food Control 24:328-335

24. Linton RH, Carter WH, Pierson MD, Hackney CR (1995) Use of a modified Gompertz equation to model nonlinear survival curves for Listeria monocytogenes Scott A. J Food Prot 58:946-954

25. Linton RH, Carter WH, Pierson MD, Hackney CR, Eifert JD (1996) Use of a modified Gompertz equation to predict the effects of temperature, $\mathrm{pH}$ and $\mathrm{NaCl}$ on the inactivation of Listeria monocytogenes Scott A heated in infant formula. J Food Prot 59:16-23

26. McDonald K, Sun DW (1999) Predictive food microbiology for the meat industry: a review. Int J Food Microbiol 52:1-27

27. McKellar RC, Knight K (2000) A combined discrete-continuous model describing the lag phase of Listeria monocytogenes. Int $\mathrm{J}$ Food Microbiol 54:171-180

28. McMeekin TA, Olley J, Ross T, Ratkowsky DA (1993) Predictive microbiology. Theory and application. Wiley, New York

29. Membré JM, Majchrzak V, Jolly I (1997) Effects of temperature, $\mathrm{pH}$, glucose and citric acid on the inactivation of Salmonella typhimurium in reduced calorie mayonnaise. J Food Prot 60:1497

30. Membre JM, Ross T, McMeekin T (1999) Behaviour of Listeria monocytogenes under combined chilling processes. Lett Appl Microbiol 28:216-220

31. Miller FA, Gil MM, Brandão TRS, Teixeira P, Silva CLM (2009) Sigmoidal thermal inactivation kinetics of Listeria innocua in broth: influence of strain and growth phase. Food Control 20: 1151-1157

32. Murphy RY, Marks BP, Johnson ER, Johnson MG (2000) Thermal inactivation kinetics of Salmonella and Listeria in ground chicken breast meat and liquid medium. J Food Sci 65:706-710

33. Nicolaï BM, Van Impe JF (1996) Predictive food microbiology. Math Comput Simul 42:287-292

34. Peleg M, Penchina CM, Cole MB (2001) Estimation of the survival curve of Listeria monocytogenes during non-isothermal heat treatments. Food Res Int 34:383-388 
35. Ross T, McMeekin TA (1994) Predictive microbiology: a review. Int J Food Microbiol 23:241-264

36. Schaffner DW, Labuza TP (1997) Predictive microbiology: where are we, and where we going? Food Technol 51:95-99

37. Skandamis PN, Davies KW, McClure PJ, Koutsoumanis K, Tassou C (2002) A vitalistic approach for non-thermal inactivation of pathogens in traditional Greek salads. Food Microbiol 19:405-421

38. Smith-Simpson S, Corradini MG, Normand MD, Peleg M, Schaffner DW (2007) Estimating microbial growth parameters from non-isothermal data: a case study with Clostridium perfringens. Int J Food Microbiol 118:294-303

39. Swinnen IAM, Bernaerts K, Dens EJJ, Geeraerd AH, Van Impe JF (2004) Predictive modelling of the microbial lag phase: a review. Int J Food Microbiol 94:137-159

40. Valdramidis VP, Belaubre N, Zuniga R, Foster AM, Havet M, Geeraerd AH, Swain MJ, Bernaerts K, Van Impe JF, Kondjoyan A (2005) Development of predictive modelling approaches for surface temperature and associated microbiological inactivation during hot dry air decontamination. Int $\mathrm{J}$ Food Microbiol 100:261-274

41. Valdramidis VP, Geeraerd AH, Bernaerts K, Van Impe JF (2006) Microbial dynamics versus mathematical model dynamics: the case of microbial heat resistance induction. Innov Food Sci Emerg Tech 7:80-87
42. Van Boekel MAJS (2002) On the use of the weibull model to describe thermal inactivation of microbial vegetative cells. Int $\mathrm{J}$ Food Microbiol 74:139-159

43. Van Impe JF, Nicolaï BM, Martens T, De Baerdemaeker J, Vandewalle J (1992) Dynamic mathematical model to predict microbial growth and inactivation during food processing. Appl Environ Microbiol 58:2901-2909

44. Walpole RE, Myers RH (1993) Probability and statistics for engineers and scientists, 5th edn. Macmillan Publishing Company, New York

45. Whiting RC, Buchanan RL (1997) Predictive modelling. In: Doyle MP, Beuchat LR, Montville TJ (eds) Food microbiologyfundamentals and frontiers. ASM Press, Washington, pp 728-739

46. Whiting RD, Cygnarowicz-Provost M (1992) A quantitative model for bacterial growth and decline. Food Microbiol 9:269-277

47. Xiong R, Xie G, Edmondson AS, Linton RH, Sheard MA (1999) Comparison of the Baranyi model with the Gompertz equation for modelling thermal inactivation of Listeria monocytogenes Scott A. Food Microbiol 16:269-279

48. Xiong R, Xie G, Edmondson AS, Sheard MA (1999) A mathematical model for bacterial inactivation. Int $\mathrm{J}$ Food Microbiol $46: 45-55$

49. Zwietering MH, Jongenburger I, Rombouts FM, Van't Riet K (1990) Modelling of the bacterial growth curve. Appl Environ Microbiol 56:1875-1881 